\title{
Gestalt-terapia e abordagem gestáltica no Brasil: análise de mestrados e doutorados (1982-2008)
}

\section{Gestalt-therapy and gestaltic approach in Brazil: masters degrees and doctorates analysis (1982-2008)}

\author{
Adriano Furtado Holanda* \\ Professor Adjunto da Universidade Federal do Paraná, UFPR - Curitiba, PR, Brasil
}

\begin{abstract}
Resumo
O artigo se propõe a uma análise qualitativa das dissertações de mestrado e teses de doutorado produzidas por programas de pós-graduação no Brasil, e que tenham tido como base de referência a Gestalt-terapia e a Abordagem Gestáltica. Foram catalogadas 51 produções, sendo 41 mestrados e 10 doutorados. Observa-se um significativo direcionamento para o debate epistemológico, com trabalhos que abordam as relações do pensamento gestaltista com diversas filosofias, bem como uma reflexão em torno de seus fundamentos. Nesse caminho, observou-se a ampliação do campo de aplicação do pensamento gestaltista para além do terreno das psicoterapias, demonstrando uma diversificação do campo. Foi identificada ainda uma série de dificuldades que a Gestalt encontra para adentrar o campo acadêmico, bem como listadas instituições e orientadores da produção atual. Pretendese com esse trabalho, traçar um perfil da Gestalt no âmbito acadêmico e apontar caminhos e direcionamentos para produções futuras.
\end{abstract}

Palavras-chave: Gestalt-terapia, Abordagem gestáltica, Mestrados, Doutorados, Produção acadêmica.

\begin{abstract}
This article has the objective to make a qualitative analysis of Masters Degrees and Doctorates produced by brazilian programs with reference in Gestalt-Therapy and Gestaltic Approach. It has been cataloged 51 productions, with 41 masters and ten doctorates. We observe a direction toward the epistemological discussion, with works that makes relation with many philosophies, and reflections around the foundations of gestaltic thinking. In this way, we observe the increasing of the field of application of gestaltic principles further psychotherapeutic ground, showing this diversification. It has been identified some difficulties that gestalt has to make more presence in academic field, and it has listed institutions of actual production. We pretend to trace the gestaltic profile in academic ground and to point some directions to future productions.
\end{abstract}

Keywords: Gestalt-therapy, Gestaltic approach, Masters degrees, Doctorates, Academic production. 
A Psicologia brasileira conheceu um significativo incremento na última década - tanto em números absolutos, como o aumento de cursos e de profissionais formados, como em diversidade - em parte devido às intensas discussões em torno das novas Diretrizes Curriculares, implementadas em 2004, através de Resolução do Conselho Nacional de Educação. As novas Diretrizes Curriculares começam a ter uma discussão mais abalizada a partir de 1999, quando são apresentadas duas versões da proposta. No ano de 2000, dois importantes documentos ampliam o debate: um documento assinado pela então Comissão de Especialistas de Ensino de Psicologia, do MEC/Sesu, que apresenta os "Padrões de Qualidade para Cursos de Graduação em Psicologia"; e a Resolução CPF 014/2000, que institui o "Título profissional de Especialista em Psicologia", editada pelo Conselho Federal de Psicologia. Esses dois momentos apontam para direções comuns, o da atenção com a qualificação profissional em Psicologia.

Esse debate sobre a formação do psicólogo brasileiro envolveu a comunidade acadêmica e profissional desde a década de 1990, se intensificando a partir de 1992, a partir da "Carta de Serra Negra", onde foram apontados encaminhamentos para a reformulação da formação do psicólogo brasileiro. Todo esse processo redundou em Fóruns de debate que traçaram metas para uma formação de qualidade. Dentre essas metas, destaca-se a formação generalista e científica, a integração entre teoria e prática, o compromisso com as demandas sociais e a expectativa de um rompimento com a perspectiva tecnicista. Tudo isto abriu espaço para uma formação antes de tudo complexa e ampliada, onde se tornou necessária a articulação entre teoria, prática e pesquisa (BERNARDES, 2004).

Diante disto, houve a necessidade ainda de se incrementar os programas de pós-graduação para se atender à demanda de novos profissionais e de novas pesquisas. Esta abertura de espaço teve seu impacto também no campo das práticas profissionais, além do âmbito da formação acadêmica. No terreno das academias, os processos avaliativos fizeram com que as instituições de ensino, em especial as privadas, redirecionassem suas perspectivas, para atender às demandas de qualificação de seu corpo docente, abrindo assim, novas searas para a formação pós-graduada. Por outro lado, no contexto profissional, observa-se uma gradual mudança de mentalidade, o que favoreceu a procura por mais qualificação, mesmo destacada do âmbito acadêmico. Assim, os mestrados e doutorados passaram a ser encarados como formações ampliadas e como campos privilegiados de debates, e não mais como terrenos exclusivos de acadêmicos, destacados do contexto pragmático.

Tudo isto se traduz em contextos de importância, quando refletimos sobre o intenso crescimento da formação em Psicologia no país. Podemos observar isto tanto no contexto da formação profissional, no âmbito da graduação, quanto no contexto da formação pós-graduada. 
Em termos de graduação, segundo dados do INEP (Instituto Nacional de Estudos e Pesquisas Educacionais Anísio Teixeira) - vinculado ao MEC - temos atualmente 356 cursos de Graduação em Psicologia, no Brasil $^{1}$. Esse número aponta para um contingente elevado de estudantes que, ao longo de cinco anos, transita pelo campo acadêmico. Desse contingente de formadores, temos que a grande maioria dos cursos encontra-se na categoria de faculdades isoladas ou centros universitários, não apresentando, portanto, envolvimento direto com a produção e a construção de conhecimento, que, por sua vez, está intimamente associada à prática da pesquisa, concentrada nas Universidades.

O que "alimenta" a formação qualificada desse corpo docente concentrado nas instituições privadas de ensino é exatamente a pósgraduação - mais destacadamente os mestrados e doutorados, que têm por função a formação para o exercício da docência e da pesquisa. Na Psicologia, temos hoje um total de 60 programas de pós-graduação no país, divididos entre mestrados (acadêmico e profissional) e doutorados, dos quais apenas 16 desses programas não estão vinculados a Universidades públicas, segundo dados da Capes $^{2}$.

É neste cenário de crescimento e de constituição de um campo de formação profissional que propomos essa discussão, com o intuito de elaborar um perfil do "estado da arte" da Gestalt brasileira, em suas múltiplas facetas, a partir de sua produção e inserção no contexto da pós-graduação.

\section{Da Relevância do Tema}

Em estudo anterior (HOLANDA; KARWOWSKI, 2004), já apontamos para uma análise qualitativa de dissertações de Mestrado e teses de Doutorado defendidas no Brasil, produzidas a partir de programas de Pós-Graduação nacionais e que partiam de uma perspectiva claramente direcionada para os princípios teóricos, técnicos e filosóficos da Gestalt-terapia e da Abordagem Gestáltica.

$\mathrm{Na}$ ocasião, o espectro do estudo abrangia, desde a primeira dissertação de mestrado defendida na USP (Universidade de São Paulo), em 1982, até o ano de 2002, com um total de 35 trabalhos. A diferença de tempo entre esse estudo e o atual - de "apenas" cinco anos - pode parecer pequena e irrelevante, todavia, como os dados mostrarão, há uma significativa distinção entre as produções atual e a anteriormente analisada, que justificam uma nova análise. Ademais, o estudo atual enquadra-se num projeto mais amplo de análise da Gestalt brasileira, e que demanda sucessivas revisões para que possamos ter um quadro efetivamente fidedigno da nossa realidade. 
Assim, o estudo que ora apresentamos principia igualmente com o trabalho "histórico" de Thérèse Tellegen (TELLEGEN, 1982), intitulado Reflexões sobre Trabalho com Grupos na Abordagem Gestáltica em Psicoterapia e Educação, e que tem uma grande representação para a comunidade gestaltista nacional: primeiro, por se tratar da autora que a tradição brasileira considera como a introdutora da Gestaltterapia no país; segundo, por ser - de fato - a primeira defesa de mestrado na área no país e, terceiro, por ser o trabalho que redundará igualmente na primeira publicação da Gestalt brasileira em formato de livro, sob o título de Gestalt e Grupos, editado em 1984 (TELLEGEN, 1984).

A listagem atual apresenta um significativo incremento - tanto qualitativo, quanto quantitativo - da produção nacional em Gestalt: são 51 trabalhos no total, com 40 mestrados e 11 doutorados. No levantamento anterior, computávamos 35 produções no total, com 31 mestrados e apenas 4 doutorados. Em apenas cinco anos, observamos um salto quantitativo de $45,7 \%$ no total de produções, e outro importante avanço, de $175 \%$ no que se refere aos doutorados, ou seja, a qualificação acadêmica cresceu em números absolutos e também em diversificação.

Uma crítica significativamente representativa que a Gestalt brasileira sofre, recai sobre sua parca produção científica (quando não se questiona sua base propriamente "científica"). A utilização de conceitos e noções específicas desta abordagem sem uma clareza sistemática de idéias e fundamentos, causa - na maioria das vezes incômodos e refrações da parte da comunidade acadêmica em geral; o que se contrapõe com o carisma e a sedução que esta abordagem provoca no meio discente.

Num rápido levantamento bibliográfico, observamos que a "cultura" gestaltista brasileira pode ser considerada como "livresca", ou seja, baseada em produções e publicações em formato de livro, em detrimento de uma produção pautada por publicações em periódicos.

De certa forma, isto também acontece com a maioria dos nossos processos formadores, ou seja, parece ser da própria "cultura" brasileira valorizar mais a produção de livros do que de artigos, como podemos observar nas instituições privadas, que são maioria no Brasil e que não possuem programas de pós-graduação atrelados à formação graduada. Isto nos remete a uma série de reflexões sobre a própria construção da universidade brasileira, mas importa aqui o fato que uma cultura acadêmica mais voltada a textos em periódicos está associada a perspectivas cientificistas e, portanto, à construção de um saber específico, enquanto que uma cultura mais livresca representa outros modos dessa construção. Sem entrarmos no âmbito mais profundo dessa discussão, convém assinalar a relação entre saber instituído e saber que se constitui a partir de pesquisas nesta comparação. 
Este fato pode ser devido a uma série de fatores que analisaremos oportunamente, mas tem implicações importantes para a construção da imagem que essa abordagem possui dentro do contexto acadêmico brasileiro, bem como tem importância capital sobre seu futuro e seu desenvolvimento. Afinal, o número elevado de cursos de graduação em Psicologia no país, forma um potencial profissional bastante elevado, o que por si só justificaria uma atenção mais ativa por parte da comunidade gestaltista brasileira sobre os modos como esta abordagem vem sendo conhecida, difundida, divulgada e construída no país.

Outro aspecto relevante concernente à apresentação dessa abordagem no Brasil nos remete ao que chamaríamos de demasiada "importação" de saber estrangeiro, com consequente relativização ou mesmo desqualificação da produção nacional. Com isto queremos assinalar que nosso nível de "importação" de conhecimento não é compatível com nossa capacidade produtiva. Isto se refere ao fato que, ao importar conhecimento, supõem-se duas possibilidades: a primeira, derivada de uma cultura colonialista, parte de uma autodesqualificação e pressupõe que não existe capacidade investigativa, o que demanda a formalização do conhecimento importado como a base; a segunda, ao contrário, se apropria do conhecimento importado com a intenção de re-criá-lo a partir de bases próprias, utilizando esse conhecimento externo como trampolim para produções próprias e autênticas.

A produção acadêmica brasileira, no geral, é de qualidade comparável aos melhores centros do mundo, o que também é verídico no tocante à Gestalt nacional. Todavia, ainda observamos dados que não refletem essa realidade. Tomemos a publicação de livros no país. Se observarmos a editora que mais publica no Brasil em matéria de Gestalt, teremos um montante editorial de 36 títulos, sendo 17 destes de autores estrangeiros e 19 de autores nacionais. Ora, somente esse número nos aponta para um dado de realidade: ainda dependemos muito de um saber importado, e na maior parte das vezes desconhecemos nossa própria produção. Desse número de produções de autores nacionais, há que se destacar a autoria de J orge Ponciano Ribeiro que, sozinho, é responsável pela publicação de sete dos dezenove títulos nacionais de Gestalt, pela mencionada editora. Num levantamento preliminar, temos um número aproximado de 98 títulos de Gestalt publicados em português, no Brasil, desde os atuais até os livros já esgotados.

Estes números importam para marcar a relevância de se fazer um levantamento da produção acadêmica em Gestalt no país, e de se divulgar essa produção para toda a comunidade científica. Em outras palavras, é relevante por apontar caminhos, tanto para novas produções - já que apresenta as diversas possibilidades de 
programas, de nomes de orientadores e de aberturas - como para trazer à tona o que já existe.

Em outras palavras, marcar o "espaço" de produção intelectual brasileiro, em matéria de Gestalt, é também marcar perspectivas para o futuro.

\section{A Delimitação do Campo do Estudo}

O estudo que estamos apresentando foi construído em múltiplas fontes. Para atualizarmos os dados apresentados em Holanda \& Karwowski (2004), fizemos a pesquisa na Biblioteca Virtual de Saúde - Psicologia (BVS-Psi), apontada no sítio www.bvs-psi.org.br, bem como a Biblioteca Digital de Teses e Dissertações, do IBICT (Instituto Brasileiro de Informação em Ciência e Tecnologia), disponível no sítio www.ibict.br. Esses dados, contudo, não dão conta da totalidade dessa produção, o que nos obrigou a acessar diversos bancos de dados das próprias instituições. Para se ter uma idéia da defasagem entre os dados disponibilizados online e os dados concretos aqui apresentados, na BVS-Psi estão listadas apenas 25 títulos relacionados a teses e dissertações com temáticas em Gestalt. Já no IBICT, temos 36 títulos, sendo que precisam ser rastreados aqueles que dizem respeito especificamente ao tema em questão, já que o unitermo "gestalt" aponta para trabalhos relacionados tanto ao Teste Visomotor Bender, quanto a estudos sobre percepção e outros que não se encaixam nesse levantamento.

O presente trabalho reproduziu a análise qualitativa do estudo anterior, centrando sua atenção sobre três eixos temáticos como modos de compreensão dos trabalhos. Esses eixos foram organizados como categorias para facilitar a apreensão dos conteúdos e das construções das diversas dissertações e teses produzidas. Esses eixos temáticos foram os seguintes: eixo "fundamentos", eixo "teoria" e eixo "técnica" (HOLANDA; KARWOWSKI, 2004).

O eixo "fundamentos" abrange os trabalhos que apontam para questões de ordem da reflexão sobre a fundamentação teórica ou filosófica da Gestalt, ou seja, que tenham conotações epistemológicas em seu bojo, enfatizando aspectos que vão desde a construção histórica dessa abordagem, até a apropriação de discussões em torno de suas bases filosóficas, enfim, que dizem respeito à sua construção enquanto campo de saber destacado. São trabalhos que apontam para preocupações tais como desenvolvimento de conceitos, alicerces teóricos, fundamentações filosóficas diversas, e que invariavelmente associam a abordagem gestaltista a modelos como a fenomenologia e as filosofias da existência. Encontramos ainda nesta categoria, temas que originalmente estão associados a outras abordagens clínicas (como é o caso de temas como transferência ou inconsciente, 
habitualmente circunscritos ao âmbito da psicanálise), bem como aproximações com teses que apontam para convergências de saberes (como no caso do construtivismo, por exemplo).

No eixo "teoria", foram agrupados aqueles trabalhos que dizem respeito às discussões sobre as bases técnicas, em geral, ou a elaboração de conceitos dirigidos à especificidade da Gestalt, abarcando temas como teoria de personalidade ou de psicopatologia, bem como aqueles relativos a uma possível reconstrução de seu saber. Em outras, palavras, esse eixo diz respeito às suas bases teóricas, além de tocar alguns campos de ampliação, como se observou no tocante à aplicação de suas teses a campos diversos da clínica, como o caso da Gestaltpedagogia.

No eixo "técnica", estão os trabalhos que fazem estudos clínicos, relatos de experiências e discussões em torno das diversas modalidades de aplicação prática da Gestalt. Envolve, pois, questões como diagnóstico, entrevista, condução de terapia (grupal ou individual), e mesmo outras áreas de aplicação que foram surgindo ao longo do tempo, como foi o caso da terapia infantil e de casal.

O que observamos com esse levantamento é que essas produções refletem muito sobre como que a abordagem em questão se organiza atualmente, e os dados apontam ainda para as lacunas e preocupações com suas articulações.

Um dos aspectos que saltam aos olhos apenas com a observação dos três eixos é o fato de haver uma significativa abertura e preocupação com questões epistemológicas, que dizem respeito à construção da Gestalt não mais como um conjunto técnico ou aplicativo à clínica, mas vislumbra-se a possibilidade de percebê-la como uma abordagem que tem muito a contribuir com a compreensão da realidade concreta do humano, enquanto ser social e cultural (HOLANDA; FARIA, 2005).

Outro aspecto relevante é o que consideramos ampliação de espectro, ou seja, a transição do entendimento de uma Gestalt concebida apenas como um método clínico, para a aplicação dos mesmos princípios a outros campos - originalmente diversos e distintos do inicialmente proposto - refletindo exatamente seu potencial epistêmico. Essa ampliação de espectro de ação da Gestalt a coloca na comunidade, no social, no campo da saúde, no hospital e outros contextos. Há ainda um outro destaque relevante: já podemos falar de uma "geração" de gestaltistas que construiu seu saber independente desde a formação graduada e que a completou com o mestrado e o doutorado, ou seja, já observamos gestaltistas doutores em Gestalt, como Ferreira (1997, 2000), Alvim (2000, 2007), Lilienthal (1997, 2003), Lima (1997, 2005), Galli $(2000,2007)$ e Vasconcelos (1994) e Tenório (2003). 


\section{Sobre as Instituições}

O mapeamento dos locais onde foram desenvolvidas as pesquisas aqui constantes serve para apontar caminhos da construção da Gestalt brasileira. Tradicionalmente, a produção de conhecimento no país tem se concentrado no eixo Rio de Janeiro/São Paulo, mas no caso da Gestalt nacional temos uma variação importante.

O estado de São Paulo ainda contribui com o maior número de teses e dissertações (no total, são 19 produções, basicamente concentradas na capital), vindo logo a seguir o estado do Rio de Janeiro e o Distrito Federal, com dez produções cada. O mais significativo desses números atualizados é exatamente o crescimento de Brasília (que até 2002 contava com apenas quatro produções), apontando para uma mudança de eixo digna de nota que, se associarmos à crescente produção do estado de Goiás, revela o Planalto Central como novo endereço da Gestalt brasileira.

\begin{tabular}{ccc|c|c|c|c|c|c|} 
TABELA & $\mathbf{1}-$ & \multicolumn{2}{c}{ MESTRADOS } & \multicolumn{3}{c}{ E DOUTORADOS } & POR & ESTADO \\
\hline & SP & RJ & DF & RS & GO & PE & SC & CE \\
Mestrado & 14 & 08 & 07 & 02 & 03 & 02 & 02 & 02 \\
\hline Doutorado & 05 & 02 & 03 & 01 & - & - & - & - \\
Total & 18 & 10 & 09 & 03 & 03 & 02 & 02 & 02
\end{tabular}

Há que se destacar que nenhuma dessas instituições possui programa de pós-graduação especificamente voltado para a Gestalt, nem mesmo contam com docentes pesquisadores-orientadores dessa abordagem, exceção feita à Universidade de Brasília (UnB), que conta com a presença de Jorge Ponciano Ribeiro, responsável pela totalidade das orientações nesta universidade. Esse é um dado relevante, que reflete - dentre outras coisas - a pequena penetração do pensamento gestaltista no contexto acadêmico. Listamos um total de 17 instituições, consoante tabela a seguir: 


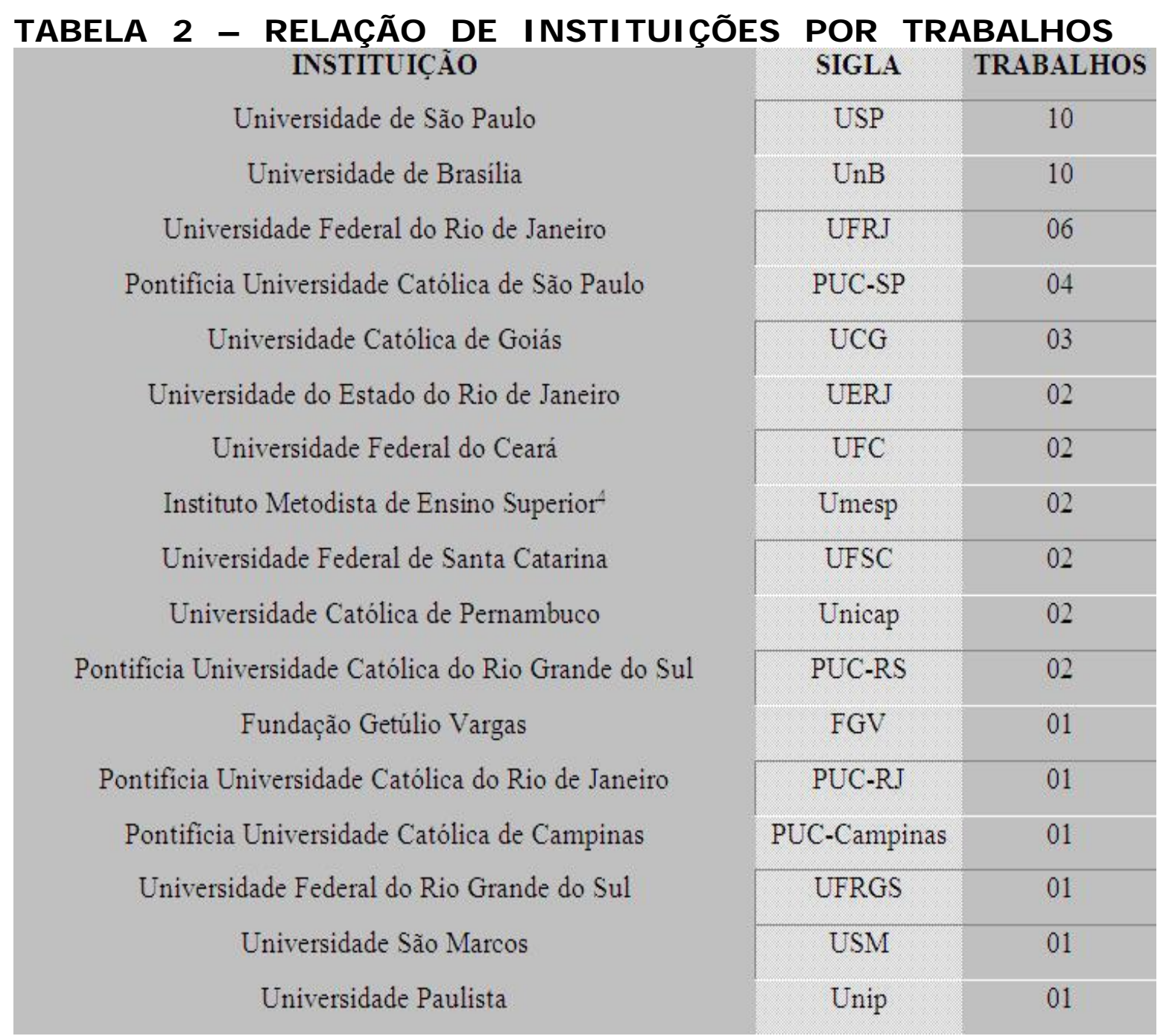

Como podemos observar na tabela acima, a Universidade de Brasília (UnB) e a Universidade de São Paulo (USP) são as instituições que mais produziram em Gestalt no país, com dez produções no total para cada uma, sendo que ambas apresentaram sete mestrados e três doutorados. Em seguida, convém destacarmos a Universidade Federal do Rio de Janeiro (UFRJ), com seis trabalhos (com quatro mestrados e dois doutorados), e a PUC de São Paulo, com quatro trabalhos (sendo dois mestrados e dois doutorados). As instituições confessionais vêm contribuindo sobremaneira para a educação brasileira, e isto é histórico. Assim, percebemos que, além das instituições católicas (como é o caso das PUCs), temos ainda programas de pós vinculados a outras dessas instituições. No estado de Goiás, temos a Universidade Católica de Goiás, que já contribuiu com três trabalhos de mestrado em Gestalt; em Pernambuco, a Universidade Católica de Pernambuco (Unicap) apresenta dois trabalhos, o mesmo numero da PUC do Rio Grande do Sul e de outra confessional, o IMES (atualmente Universidade Metodista de São 
Paulo, UMESP). Nas entidades públicas, temos ainda, com dois trabalhos, a Universidade Estadual do Rio de Janeiro, as Federais do Ceará e de Santa Catarina.

Observamos com isto que o eixo tradicional de produção científica na Gestalt permanece associado aos estados do Rio de Janeiro e de São Paulo, com um importante deslocamento para o Distrito Federal. Estados tradicionais como Rio Grande do Sul e Santa Catarina apresentam produção similar aos estados de Goiás, Pernambuco e Ceará.

Em termos de uma "geografia" da Gestalt acadêmica brasileira, a região sudeste domina amplamente (com 29 produções), sendo seguida pela região Centro-Oeste (com treze produções, no total). Não há nenhuma produção nesse contexto, na região Norte (em parte devido ao fato que só existem dois programas de pós-graduação nessa região, ambos na UFPA, sendo um deles associado às ciências comportamentais). Mas destacamos ainda as similaridades entre as produções do Nordeste (quatro) e da região Sul (cinco).

Talvez seja interessante assinalar que, dos 60 programas de pósgraduação no Brasil, a distribuição corresponde aos seguintes números: 33 destes estão concentrados na região Sudeste (sendo dezoito no estado de São Paulo, oito no Rio de Janeiro, cinco em Minas Gerais e dois no Espírito Santo). O Nordeste já apresenta onze programas no total, divididos entre os estados de Pernambuco (com três), Rio Grande do Norte, Ceará e Paraíba (com dois cada) e Bahia e Sergipe, com um. A região Centro-Oeste e a região Sul apresentam o mesmo número de programas - sete no todo, divididos entre o Distrito Federal (com cinco) e os estados de Goiás e Mato Grosso do Sul (com um cada), Rio Grande do Sul (quatro), Paraná (dois, sendo ambos do interior) e Santa Catarina (um). Isso ajuda a explicar a distribuição das produções em Gestalt no Brasil, a apontam para outras possibilidades de acolhimento desse pensamento no contexto acadêmico.

\section{Sobre a Área de Defesa e sobre os Orientadores}

Dos trabalhos em Gestalt, a grande maioria encontra-se vinculado a programas de pós-graduação em Psicologia, num total de 41. Todavia, temos um representativo número de dez trabalhos relacionados em programas de áreas distintas, como educação, filosofia, comunicação social, ergonomia e ciências da religião.

O primeiro trabalho apresentado fora do contexto da psicologia foi realizado na área da Educação, embora tenha uma temática tipicamente clínica. Trata-se da dissertação de mestrado intitulada $\mathrm{O}$ Processo de Cooperação na Psicoterapia de Grupo em Gestalt-terapia, defendida na Universidade Federal do Ceará, em 1992 (BORIS, 
1992). Isso aponta para alguns fatores que serão encontrados em outros trabalhos, que são: a ausência de programas de pósgraduação em Psicologia em determinadas regiões geográficas (o que obriga a uma migração para outras áreas do conhecimento); a inexistência de docentes disponíveis ou capacitados para orientar temáticas dessa natureza (mesmo quando existem programas de pós em Psicologia); e a necessidade de se desenvolver autonomia na construção do pensamento gestaltista.

Se por um lado isso aponta para um conjunto de "deficiências", por outro, abre espaços de interlocução por demais importantes e interessantes para nossa abordagem. Tendo em vista que no contexto global das influências que marcam o edifício da abordagem gestaltista encontramos pensamentos diversos - tais como teatro, arte, filosofia, etc. - essa perspectiva de aplicar a Gestalt a outras áreas, fora da Psicologia, se torna uma opção considerável e, diríamos mesmo, desejável, dado que vai ao encontro de uma idéia de multiplicidade e diversidade, constantemente presente em suas bases.

O segundo trabalho apresentado fora da área psicológica foi o mestrado em Filosofia, defendido em 1998, intitulado A Gestaltterapia no Envio da Modernidade: Teoria e Técnica na Confrontação da Dor, na Universidade do Estado do Rio de Janeiro (CAVANELLAS, 1998). A seguir temos ainda mais três trabalhos defendidos em programas de Educação (CARDELLA, 1999; ROCHA, 2001; COSTA, 2002); mais um em Filosofia (GRANZOTTO, 2005); dois em Comunicação Social (GALLI, 2000, 2007); um em Ergonomia (BONMANN, 2001); e um em Ciências da Religião (PINTO, 2007). Vale destacar que dois desses trabalhos apresentados "fora" da Psicologia, são de doutorado (GALLI, 2007; PINTO, 2007).

O fato de termos esse número de trabalhos apresentados em outras áreas é significativo, pois tradicionalmente a Gestalt tem uma marca associada à clínica psicológica, e mais especificamente à psicoterapia. Isto também pode ser constatado pelos trabalhos apresentados em mestrados e doutorados no Brasil (basta observarmos o primeiro trabalho aqui listado fora da área da psicologia).

De qualquer modo, observamos que a Gestalt se diversifica, mais claramente pela ótica pedagógica, orientando-se para a Gestaltpedagogia, como temos em três trabalhos de mestrado (LILIENTHAL, 1997; BONMANN, 2001; COSTA, 2002), e um de doutorado (LILIENTHAL, 2004), colocando a área da educação como alternativa natural de aplicação da Gestalt. Além dos supracitados trabalhos, podemos ainda citar essa vinculação com a Educação em outras produções, vinculadas à Psicologia, que tratam de: trabalhos de grupos em psicoterapia e educação (TELLEGEN, 1982); aprendizagem experiencial (FRAZÃO, 1983); e oficina criativa e formação de educadores (CARVALHO, 2000). 
Há que se destacar ainda algumas inovações na aplicação da Gestalt, como é o caso da dissertação de mestrado em Educação de Rocha (2001), que trabalha questões de gênero, intitulada Psicogênese da Masculinidade: Uma leitura gestáltica sobre a construção da identidade do gênero masculino em diversas teorias e sua importância para a escola.

Essa diversificação que estamos apresentando, vai além das áreas distintas de pós que, como assinalamos, tem mais a ver com dificuldades relacionadas às burocracias dos programas do que propriamente com buscas inovadoras. Essas inovações vêm sendo construídas dentro mesmo do terreno da prática psicológica, como é o caso das novas interlocuções que a Gestalt vem apresentando.

Um excelente exemplo dessa inovação pode ser constatado através da idéia de tomar a Gestalt como possível instrumento para a paz, como no mestrado de Fittipaldi (2001), intitulado Construindo uma Cultura de Paz: a Abordagem Gestáltica como um Instrumento; ou a partir da entrada do pensamento gestaltista em áreas outras como hospital - através da psicossomática (IVANCKO, 2006) - ou mesmo no terreno das Organizações (ALVIM, 2000). Outros campos possíveis de interlocução se abrem como o diálogo com o Zen (VERAS, 2005), com a comunicação (GALLI, 2007) ou com a arte (ALVIM, 2007).

Mas, sem dúvida, se há um novo campo - inovador e significativo - é o da interlocução com a religiosidade e com a espiritualidade, por trazer ao terreno da psicologia uma leitura dinâmica desse fenômeno (MORAES, 2002; CARVALHO, 2005; PINTO, 2007).

Apesar dessas manifestações de diversidade, ainda predominam os trabalhos na área da clínica psicoterapêutica, como a psicoterapia em geral (TÁVORA, 1994; LIMA, 2005; ANDRADE, 2007), psicoterapia de curta duração (PINTO, 2007), psicoterapia de casal (SILVEIRA, 1998), terapia familiar sistêmica (PHILIPPI, 2004), de grupos (TELLEGEN, 1982; LIMA, 1988; BORIS, 1992) ou infantil (COSTA, 2003).

Contudo, há que se notar o debate em torno de questões epistemológicas que, desde os primeiros trabalhos, vem caracterizando a produção nacional em Gestalt. Já em 1989 temos a apresentação do primeiro trabalho de mestrado com uma orientação voltada para o debate epistemológico, intitulado Bases Filosóficas e Implicações Técnicas na Gestalt-terapia (PORTO, 1989). Essa preocupação se repete ainda em diversos trabalhos, seja num contexto de discussão de seus fundamentos (TÁVORA, 1994; LIMA, 1997; FERREIRA, 2002), na articulação com outras filosofias, como o Zen (VERAS, 2005) ou a Fenomenologia (CAVANELLAS, 1998; PENTEADO, 1998; KARWOWSKI, 2001; GRANZOTTO, 2005; ALVIM, 2007; GALLI, 2007).

Um outro destaque importante refere-se à questão dos orientadores. A mesma problemática observada com respeito aos programas de 
pós é observada em relação aos orientadores. Um dado que aponta para a pouca penetração que a Gestalt tem na academia, é a ausência de orientadores especificamente dedicados à abordagem gestáltica. Com isto, invariavelmente, os trabalhos de mestrado e de doutorado são orientados por docentes que têm aproximações teóricas ou, quando isto não acontece, dedicados a especificidades do próprio programa. Dentre os nomes de orientadores que encontramos na relação de mestrados e doutorados aqui nesse trabalho, o único que se constitui especificamente como gestalt-terapeuta e como orientador-docente, é o nome de Jorge Ponciano Ribeiro, vinculado à Universidade de Brasília, e que igualmente é o responsável pelo maior número de orientações na área, com um total de dez (a totalidade dos trabalhos do Distrito Federal e da UnB).

O nome de Élida Sigelmann, da UFRJ, encontra-se vinculado a cinco orientações - correspondendo ao segundo maior número - e representa uma dessas aproximações teóricas a que nos referimos, sendo conhecida por suas leituras associadas às psicologias de base humanista. Apesar desses dois nomes (os mais produtivos em termos de orientações) representarem dois caminhos de excelência, a constatação negativa é o fato de ambos encontrarem-se aposentados, portanto, atualmente distanciados dessa produção.

Em relação aos demais nomes de orientadores, temos a destacar os doutores Norberto de Abreu e Silva (atualmente vinculado ao programa de pós-graduação da UnB, mas tendo orientado trabalhos na USP) e de Henriette Morato (USP), com três trabalhos orientados cada. Com dois trabalhos, temos os nomes de Adriano Holanda (pela UCG), Marília Ancona Lopez (PUC-SP) e Therezinha Moreira Leite (USP). Os demais orientadores são: Ana Maria Loffredo (USP), Christina Menna Barreto Cupertino (Unip-SP), Cristina M.S.Brito Dias (Unicap), Eda Marconi Custodio (IMES-SP), Elisa Medici Pizão Yoshida (PUC-Campinas), Esdras Guerreiro Vasconcellos (PUC-SP), Franco Lo Presti Seminério (FGV), João Edênio dos Reis Valle (PUC-SP), Lea da Cruz Fagundes (UFRGS), Luiz Felipe Baeta Neves Flores (UERJ), Marco Antonio Frangiotti (UFSC), Maria Beatriz Furtado Rahde (PUCRS), Maria Luisa Sandoval Schmidt (USP), Marília Gouvêa (UCG), Marília Martins Vizzotto (IMES-SP), Mitsuko Aparecida Makino Antunes (Unimarco), Nilce Pinheiro Mejias (USP), Roberto Porto Simões (PUC-RS), Silvia Helena Vieira Cruz (UFC), Susana Vasconcelos Jimenez (UFC), Telma Donzelli (UERJ), Terezinha Féres Carneiro (PUC-RJ), Ued Martins M. Maluf (UFRJ), Vânia Ribas Ulbricht (UFSC).

\section{Sobre o Ano de Defesa}

Como já assinalamos anteriormente, o primeiro trabalho de mestrado em Gestalt, defendido no Brasil foi no ano de 1982, de 
autoria de Thérèse Tellegen, na USP. A data corresponde a uma década de distância do primeiro artigo publicado em Gestalt-terapia no país, também de autoria de Tellegen (1972), e que consta como a primeira referência à Gestalt oficialmente no Brasil. Esse artigo - hoje uma referência clássica - foi o primeiro a ser publicado no país, e corresponde à sua participação em um Ciclo de Estudos, sobre "temas atuais em psicoterapia", promovido pela Sociedade de Psicologia de São Paulo (COIMBRA, 1992; Kiyan, 1998, 2001; GOMES, 2001; Karwowski, 2001; Holanda \& Karwowski, 2004; COSTA, 2008).

A década de 1980 pode ser considerada como o período de "entrada" da Gestalt na academia brasileira, dado que após esse trabalho seminal de Tellegen (1982), tivemos ainda cinco outras produções de mestrado, totalizando quatro trabalhos na década. Há que se destacar que os três primeiros trabalhos de mestrado em Gestalt no Brasil tenham tido o tema dos grupos como foco (TELLEGEN, 1982; FRAZÃO, 1983; LIMA, 1988). Além disso, temos ainda nessa mesma década, o primeiro trabalho que manifesta uma preocupação epistemológica com a abordagem gestáltica, versando sobre suas bases filosóficas (PORTO, 1989).

Os trabalhos defendidos nessa década apontam ainda para outra realidade: a Gestalt brasileira rapidamente se disseminou pelos estados, como podemos observar pelo fato que os primeiros dois trabalhos acadêmicos tiveram sua vinculação com o estado de São Paulo, mais particularmente a USP, enquanto os demais foram defendidos na UnB (em Brasília) e na FGV (no Rio de Janeiro).

A primeira tese de doutorado com temática relativa à Gestalt foi 0 trabalho de Ana Maria Loffredo, intitulado De Cotovelos Apoiados no Para-Peito da Palavra: Do Cenário Clínico, Qual é o Horizonte?, e defendido na Universidade de São Paulo, em 1992 (LOFFREDO, 1992). Esse foi um trabalho interessante, que marcou também uma articulação pouco tratada no seio do pensamento gestaltista, que são as interlocuções entre a Gestalt-terapia e a Psicanálise. Podemos considerar esse trabalho também num contexto epistemológico, marcando a reflexão sobre seus fundamentos desde seus primórdios no Brasil. Essa reflexão epistemológica pode ser ainda considerada uma marca da Gestalt brasileira - como veremos mais adiante corroborando com a idéia que o Brasil produz um pensamento, na Gestalt, muito mais fundamentado do mesmo no seu país de origem. A década de $1990^{3}$ apresenta um primeiro impulso para a Gestalt brasileira, com vinte e um trabalhos produzidos, sendo 19 mestrados e dois doutorados. Observam-se nesta década, três períodos distintos: entre 1991 e 1994, tivemos a apresentação de oito trabalhos; um interlúdio "improdutivo" nos anos 1995-1996, e outro "salto" de produção nos três últimos anos da década, com dez trabalhos apresentados. Colocamos aqui o comentário para os anos 
95-96 entre aspas, porque obviamente não se trata de falta de produção, mas antes de preparação para o ano de 1997, quando tivemos a apresentação de cinco mestrados (gestados ao longo desses dois anos anteriores).

Um outro destaque para os trabalhos dessa década é a tese de doutoramento de Cecília Coimbra - intitulada Gerentes da Ordem: algumas práticas "psi" nos anos 70 no Brasil, e defendida na USP que, apesar de não versar específica e exclusivamente sobre a Gestalt-terapia, trata da construção da psicologia brasileira durante a década de 1970, e traça um importante histórico das práticas humanistas (aqui inclusa a Gestalt-terapia) nesse período, que coincide ainda com a "chegada" dessa abordagem ao país.

Os anos 2000 já nascem sob a influência das discussões em torno das novas diretrizes para o ensino e, portanto, apontam para a necessidade de uma maior qualificação profissional (em especial dos docentes). Isso é uma das razões que explica o aumento representativo de produções em Gestalt nessa década, ultrapassando inclusive a produção da década anterior. O mais significativo desse período, é o fato de termos tido - até então - nove teses de doutorado defendidas, além de quinze mestrados (quase o mesmo montante da década anterior, sendo que ainda restam três anos para desenvolver).

A seguir, apresentamos a tabela com as produções a cada década:

\begin{tabular}{c|ccc} 
TABELA 3 & $\begin{array}{r}\text { MESTRADOS } \\
\text { Anos 1980 }\end{array}$ & $\begin{array}{r}\text { DOUTORADOS } \\
\text { Anos 1990 }\end{array}$ & $\begin{array}{c}\text { POR DÉCADAS } \\
\text { Anos 2000 }\end{array}$ \\
\hline Mestrado & 06 & 19 & 15 \\
Doutorado & 00 & 02 & 09 \\
Total & 06 & 21 & 24 \\
\hline
\end{tabular}

Observemos que a década de 2000 já ultrapassa - em números brutos - a produção da década anterior. Lembremos ainda que, não estão aqui listados aqueles trabalhos inconclusos - recémprincipiados ou em andamento - mas tão somente os mestrados e doutorados já defendidos até esta data. Temos notícias de mestrados com previsão de defesa ainda para o ano de 2008, mas até o presente momento a listagem comporta apenas as defesas oficializadas.

A demanda por qualificação proposta pelas novas diretrizes para os cursos superiores coincide ainda com a abertura de um número muito grande de cursos de psicologia em faculdades particulares, o que levou a uma absorção maior de mão-de-obra especializada. Ademais, as novas diretrizes igualmente abriram perspectivas mais 
alvissareiras para as abordagens de cunho humanista e, principalmente, para aquelas que têm a fenomenologia como substrato filosófico ou metodológico (dentre as quais se encaixa a Gestalt), fazendo com que em cada curso houvesse - pelo menos uma ou duas disciplinas disponíveis para se desenvolver um pensamento tal qual a Gestalt. Isso também ajuda a explicar a maior procura por qualificação e, portanto, por mestrados e doutorados, cada vez mais exigidos pelos critérios de pontuação das instâncias avaliadoras.

A seguir, temos o quadro destas produções ano a ano:

\section{TABELA 4 - MESTRADOS E DOUTORADOS ANO A ANO}

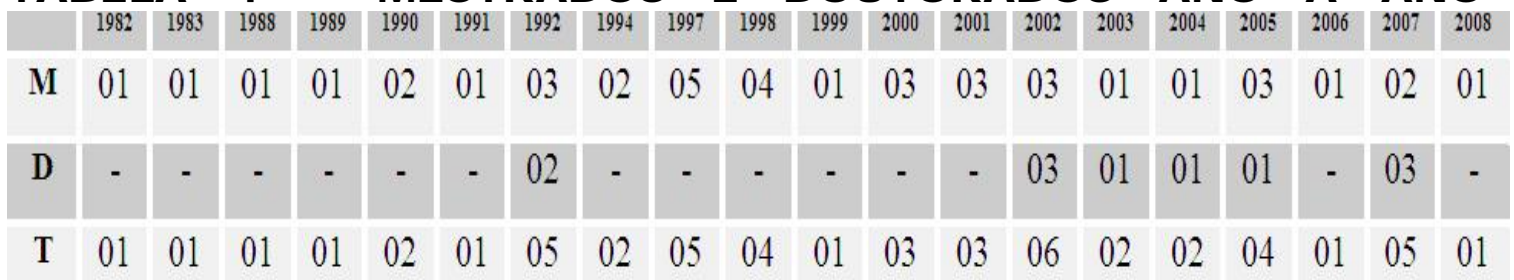

Observemos ainda que as defesas de teses de doutorado, inicialmente se dão num espaço de dez anos, para depois conhecer uma pequena regularidade. Apesar de ainda haver pouca inserção da abordagem gestáltica nas Universidades - aqui compreendidas como aqueles centros ${ }^{4}$ que integram ensino, pesquisa e extensão - já podemos observar uma preocupação com uma maior consistência teórica e técnica para esse trabalho.

Um questionamento bem objetivo pode ser dirigido ao número crescente - mas ainda limitado de produções nesse contexto acadêmico por parte da Gestalt. A esse questionamento atribuímos algumas "causas", como: a) em primeiro lugar, temos uma "tradição" antiintelectualista encontrada particularmente na psicologia humanista americana (no seio da qual a Gestalt-terapia se insere a partir da década de 1960), que se construiu no embate contra o tecnicismo ou o objetivismo das abordagens behaviorista ou analítica, e que privilegiou em demasia os aspectos vivenciais em detrimento da reflexão crítica (COIMBRA, 1992; HOLANDA, 2005; GOMES, HOLANDA \& GAUER, 2004a, 2004b); b) em segundo lugar, a abordagem gestáltica, por haver se constituído primordialmente como uma clínica, igualmente se distanciou da produção teórica ou mesmo da reflexão empírica. Além disso, no Brasil, há tradicionalmente uma cisão entre a prática profissional e a pesquisa empírica, criando uma idéia errônea (e disseminada principalmente pelos clínicos), que assinala que o "fazer" da clínica e "fazer" da pesquisa se constituem em coisas separadas; e c) ainda se observa um predomínio das abordagens psicodinâmicas no contexto acadêmico brasileiro, dificultando a abertura a novas perspectivas. 
De qualquer modo, os números mostram que há uma demanda crescente por qualificação, o que aponta para mais possibilidades nos anos vindouros.

\section{Aproximações e Considerações Finais}

Gostaríamos de destacar agora algumas correlações que consideramos importantes, e que os dados nos apresentam. Retomemos os "eixos" anteriormente propostos. Encontramos poucas referências ao eixo "teoria" como proposições de trabalhos. Uma crítica recorrente que a Gestalt recebe diz respeito à sua parca teorização. Já afirmamos em trabalho anterior (HOLANDA, 2005), que a Gestalt realmente apresenta algumas deficiências teóricas - como a ausência de uma clara teoria de desenvolvimento ou de psicopatologia - que dificultam sua absorção no meio acadêmico.

Uma discussão de suas bases teóricas seria de grande relevância para a abordagem, daí o destaque para aquelas produções que, direta ou indiretamente, tocam essas questões. Tendo em vista essas limitações apresentadas pela teoria num contexto global, é interessante notar alguns trabalhos que se dirigem para esse caminho, como a discussão em torno de uma possível aproximação entre a Gestalt e a Teoria das Relações Objetais de Fairbain, como base para uma construção de uma teoria de psicopatologia (TENÓRIO, 2003); ou as interlocuções propostas entre a abordagem gestáltica e as Abordagens Sistêmicas Construtivistas Construcionistas Sociais (PHILIPPI, 2004).

Essas leituras ou aproximações são importantes para dar continuidade ao debate em torno da teorização da abordagem gestáltica, em especial para suprir as necessidades surgidas da dinâmica da ciência. Vasconcelos (1994) apresenta em sua dissertação de mestrado exatamente uma discussão em torno da questão da psicopatologia, a partir da teoria do ciclo do contato. Igualmente a questão da formação do terapeuta em Gestalt (CARDELLA, 1999) ou as implicações dessa abordagem para a psicossomática (IVANCKO, 2006).

Convém destacar as discussões em torno da Gestaltpedagogia, que tanto podem ser entendidas como "teoria" ou como "técnica". No caso de Costa (2002), a Gestaltpedagogia aparece como uma possibilidade de leitura das próprias bases teóricas da abordagem.

Já a discussão sobre aspectos técnicos pode transcender campos. Observamos que as diversas aplicações da Gestalt vêm sendo temas constantes de preocupação e de exposição. Poderíamos destacar isso como uma ampliação de campo, que representa essa transcendência do campo clínico à qual a Gestalt esteve associada classicamente inclusive na sua própria terminologia, como Gestalt-terapia, passando 
a ser vista posteriormente com abordagem gestáltica - para uma leitura mais complexa da realidade psicológica. Assim, temos que citar as diversas modalidades de aplicação a campos diversos, como é o caso da Gestalt no terreno das organizações (ALVIM, 2000), da Gestalt no hospital (IVANCKO, 2006) ou na educação, com a Gestaltpedagogia (BONMANN, 2001; LI LIENTHAL, 2004).

O campo da clínica tradicional ainda se mantém produtiva, com temas diversos, desde a psicoterapia em geral (ANDRADE, 2007), os processos de grupo (TELLEGEN, 1982; LIMA, 1988; BORIS, 1992), a psicoterapia de família (SILVEIRA, 1998) ou a psicoterapia infantil (LIMA, 2002; COSTA, 2003). Questões mais específicas da aplicação técnica da Gestalt também são destacadas, como a orientação vocacional (FERREIRA, 1997) ou o diagnóstico (QUADROS, 1991; PIMENTEL, 2002).

Diante da insuficiência de debates teóricos na Gestalt, há que se assinalar para dois trabalhos que apontam caminhos interessantes de análise: trata-se dos trabalhos de mestrado de Zlotnic (1990), intitulado Gestalt-terapia e Transferência: Aquisição de Conceitos na Formação de Psicólogos, e o de Penteado (1998), cujo tema foi O Conceito de Inconsciente na Gestalt-terapia. Ambos tratam das estreitas relações entre a Gestalt e a Psicanálise, bem como analisam aspectos relevantes da teoria e a prática dessa abordagem, constituindo-se em documentos de extrema importância para a construção de um saber solidificado na Gestalt.

E um último destaque com relação a esse ponto é a já mencionada aproximação da Gestalt com a religiosidade, tanto no terreno da prática clínica, como no campo da interlocução entre saberes. Destacamos, pois, três trabalhos nesse caminho: um de mestrado, intitulado Análise de um Caso à Luz da Teoria do Ajustamento Criativo da Gestalt-terapia: Fenomenologia da Experiência Religiosa (CARVALHO, 2005), e duas teses de doutorado, Trabalhando com os Fenômenos Religiosos e Espirituais: Uma proposta metodológica para avaliação da experiência de ampliação de consciência no processo grupal (MORAES, 2002) e Gestalt-terapia de Curta Duração para Clérigos Católicos: Elementos para a prática clínica (PINTO, 2007). Esses trabalhos marcam um entrelaçamento entre a teoria e a prática, por um lado, e o debate epistêmico, por outro; além de apontar para o um potencial que a Gestalt possui de se constituir num discurso privilegiado para uma leitura mundana.

E é exatamente no contexto epistemológico - marcado pelo "eixo" dos fundamentos - que encontramos uma grande concentração de trabalhos, o que nos aponta para uma característica singular da Gestalt brasileira, que se preocupa com seus fundamentos, especialmente no que tange o debate filosófico.

Maior destaque para as relações com a Fenomenologia. Esta vem sendo debatida tanto no seu caráter metodológico, quanto nos seus 
aspectos propriamente filosóficos. Neste sentido, temos aproximações interessantes com o pensamento de Heidegger (CAVANELLAS, 1998; GALLI, 2007), ou a apropriação da fenomenologia no contexto da formação (KARWOWSKI, 2001). Não encontramos referências específicas às bases da Fenomenologia, como presentes nos pensamentos de Brentano ou de Husserl, ou mesmo outras interlocuções mais contemporâneas como Sartre ou Scheler, mas há uma tendência à aproximação com o pensamento de Merleau-Ponty (GRANZOTTO, 2005; ALVIM, 2007), já observada, pela primeira vez, em Penteado (1998). Igualmente sentimos falta de aproximações ou interlocuções com outras teorias mais claramente designadas como base da Gestalt, como as Teorias de Campo de Kurt Lewin ou mesmo a Organísmica de Goldstein, embora esta última tenha referência em Lilienthal (2004). Também no campo da leitura existencialista, destacamos a ausência de trabalhos que tenham como referência direta $o$ pensamento de Martin Buber, continuadamente citado como fundamento da Gestalt. Algumas referências indiretas foram encontradas, como em Costa (2002), mas trabalhos que tenham a filosofia dialógica como meta somente foram encontrados em autores que não se apropriam da Gestalt - embora a citem - diretamente, de modo a entrar em nosso levantamento (como encontramos em KATO, 1991 ou HOLANDA, 1993).

No debate com o método de pesquisa de orientação fenomenológica, ainda teríamos que destacar aqueles trabalhos que o têm como base (MORAES, 2002; CARVALHO, 2005; ANDRADE, 2007; COSTA, 2008), ou seja, que têm a fenomenologia como sustentáculo metodológico para sua pesquisa.

Em termos de pesquisa empírica, ainda não encontramos grandes referências. Isto parece estar associado ao processo de construção da Gestalt, como uma abordagem que se mostrou, tradicionalmente, refratária a acomodações metodológicas ou a perfis de ciência específicos, o que fez com que não se cultivasse uma cultura científica na abordagem. Percebe-se mesmo uma certa incompreensão no seio da comunidade quanto ao caráter do que é "científico" ou que possa vir a ser considerado como tal. Isso explica a pouca produção em termos empíricos. Todavia, a apropriação das metodologias qualitativas de pesquisa vem suprindo essa lacuna paulatinamente, como observamos com a metodologia fenomenológica supracitada, bem como os estudos historiográficos (KYIAN, 1998; GOMES, 2001; COSTA, 2008).

Ainda no que se refere ao debate sobre os fundamentos da Gestalt, há que se destacar os trabalhos de contextos distintos, como a perspectiva gestáltica na direção de uma cultura de paz (FITTIPALDI, 2007), ou o trabalho intitulado llumina-ação: diálogos entre a Gestalt-terapia e o Zen-Budismo (VERAS, 2005). 
Uma questão relativamente "crítica" na Gestalt é a sua herança psicanalítica. Isto se observa tanto na história de sua construção enquanto abordagem autônoma, como na própria vida pessoal de Fritz (PERLS, 1979). Nesse sentido, consideramos o debate com a psicanálise como de extrema importância para a Gestalt. A Psicanálise - embora tenha sido uma das principais referências dos Perls, em especial de Fritz, e esteja presente constantemente no bojo da teoria e da prática da Gestalt-terapia - aparecem ao largo das análises diversas. Encontramos significativas referências a ela, tais como as presentes nos trabalhos de Loffredo (1992, 1994), ou de modo menos afirmativo, com aproximações diversas, como em Tenório (2003). De modo mais aprofundado, encontramos essas referências e aproximações nos trabalhos de Loffredo (1992), ou nas discussões sobre o inconsciente (PENTEADO, 1998) ou sobre a transferência (ZLOTNIC, 1990).

Um derradeiro destaque merece nota. Apesar de observarmos uma produção acadêmica ainda incipiente, tanto no que tange ao número de mestrados e doutorados, num contexto geral, quanto ao volume ainda reduzido de artigos científicos em matéria de Gestalt no Brasil (objeto de um outro estudo), uma perspectiva que se abre é o fato de muitas dessas produções aqui analisadas se tornarem livros (TELLEGEN, 1984; LOFFREDO, 1994; COIMBRA, 1995; KYIAN, 2001; CARDELLA, 2002; LIMA FILHO, 2002; PIMENTEL, 2003; KARWOWSKI, 2005; MÜLLER-GRANZOTTO \& MÜLLER-GRANZOTTO, 2007). Isto tem um duplo impacto: por um lado, é positivo por apresentar-se como possibilidade de fomentar novos debates; por outro lado, remete-nos ao que comentávamos no princípio desse artigo, que é a cultura "livresca" e pouco comprometida tanto com a pesquisa, quanto com a revisão de idéias.

Diante desse quadro, esperamos que este trabalho tenha podido traçar um perfil dos caminhos que a Gestalt vem trilhando no meio acadêmico, na atualidade, bem como tenha possibilitado o vislumbre de novas aberturas para o futuro. Dada a complexidade e a diversidade de seus fundamentos, a Gestalt nos aparece como uma excepcional opção ao hermetismo academicista ou às ideologizações comuns das "correntes" psicológicas, bastando para tal, caminhar na direção de seus princípios mais fundamentais e que consideramos os mais importantes: totalidade, diálogo e dialética.

\section{Referências Bibliográficas}

ALVIM, M.B. Ato Artístico e Ato Psicoterápico como Experimentação: diálogos entre a fenomenologia de Merleau-Ponty, a arte de Lygia Clark e a Gestalt-terapia. 2007. 374f. Tese (Doutorado em Psicologia Clínica) - Universidade de Brasília, Brasília. 
Ensaio para um Modelo Psicológico de Análise Organizacional na Perspectiva da Abordagem Gestáltica. 2000. 263f. Dissertação (Mestrado em Psicologia) - Universidade de Brasília, Brasília.

ANDRADE, C.C. A Vivência do Cliente no Processo Psicoterapêutico: Um estudo fenomenológico na Gestalt-terapia. 2007. 261f. Dissertação (Mestrado em Psicologia Clínica) Universidade Católica de Goiás, Goiânia.

BAFFILE, S.N. Interrupção do Processo Psicoterapêutico: uma abordagem gestáltica. 1997. 114f. Dissertação (Mestrado em Psicologia) - Instituto Metodista de Ensino Superior, São Bernardo do Campo.

BERNARDES, J. S. O Debate Atual sobre a Formação em Psicologia no Brasil - permanências, rupturas e cooptações nas políticas educacionais. 2004. 207f. Tese (Doutorado em Psicologia Social) - PUC-São Paulo, São Paulo.

BONMANN, R.D. O Uso da Gestaltpedagogia no Desenvolvimento das Inteligências Múltiplas Aplicada no Processo de Ensino-Aprendizagem. 2001. 99f. Dissertação (Mestrado em Ergonomia) - Universidade Federal de Santa Catarina, Florianópolis.

BORIS, G.D.J.B. O Processo de Cooperação na Psicoterapia de Grupo em Gestalt-terapia. 1992. 276f. Dissertação (Mestrado em Educação) - Universidade Federal do Ceará, Fortaleza.

CARDELLA, B.H.P. A Formação do Psicoterapeuta. Uma abordagem gestáltica. São Paulo: Summus, 2002.

. A Incorporação do Conhecimento como Criação de Si Mesmo na Formação do Gestalt-terapeuta. 1998. $176 \mathrm{f}$. Dissertação (Mestrado em Educação) - Universidade Paulista, São Paulo.

CARVAlHO, M.A.B. Análise de um Caso à Luz da Teoria do Ajustamento Criativo da Gestalt-terapia: Fenomenologia da Experiência Religiosa. 2005. 217f. Dissertação (Mestrado em Psicologia Clínica) - Universidade de Brasília, Brasília.

CAVANELLAS, L.B. A Gestalt-terapia no Envio da Modernidade: Teoria e Técnica na Confrontação da Dor. 1988. 99f. Dissertação (Mestrado em Filosofia) - Universidade do Estado do Rio de Janeiro, Rio de Janeiro.

COIMBRA, C.M.B. Gerentes da Ordem: algumas práticas "psi" nos anos 70 no Brasil. 1992. 437f. Tese (Doutorado em Psicologia) Universidade de São Paulo, São Paulo.

.Guardiães da Ordem: uma viagem pelas práticas psi no Brasil do milagre. Rio de Janeiro: Oficina do Autor, 1995.

COSTA, D.S.M. História da Gestalt-terapia no Brasil contada por seus "Primeiros Atores": Um estudo historiográfico no eixo São 
Paulo-Brasília. 2008. 69f. Dissertação (Mestrado em Psicologia) Universidade Católica de Goiás, Goiânia.

COSTA, M.I.M. A Prática da Psicoterapia Infantil a partir do Referencial Teórico do Psicodrama, Gestalt-terapia e Abordagem Centrada na Pessoa, sob as óticas de Bermúdez, Ferrari, Oaklander e Axline. 2003. 269f. Dissertação (Mestrado em Psicologia Clínica) - Universidade Católica de Pernambuco, Recife. COSTA, V.E.S.M. A Relação Professor-Aluno a partir da Gestaltpedagogia: A Vivência da Intersubjetividade como um Elemento Significativo para a Aprendizagem. 2002. 109f. Dissertação (Mestrado em Educação) - Universidade Católica de Goiás, Goiânia.

FERREIRA, I.B. A Fluidez do Ser em Gestalt-terapia. 2002. $132 \mathrm{f}$. Tese (Doutorado em Psicologia) - Universidade Federal do Rio de Janeiro, Rio de Janeiro.

.A Orientação Vocacional Clínica - Por um Mundo em Transformação. 1997. 117f. Dissertação (Mestrado em Psicologia) Universidade Federal do Rio de Janeiro, Rio de Janeiro .

FITTIPALDI, A.Q. Construindo uma Cultura de Paz: a Abordagem Gestáltica como um Instrumento. 2007. 123f. Dissertação (Mestrado em Psicologia Clínica). Universidade de Brasília, Brasília.

FRAZÃO, L.M. Modelo de Aprendizagem Experiencial Aplicado ao Ensino de Terapia de Grupo. 1983. 191f. Dissertação (Mestrado em Psicologia) - Universidade de São Paulo, São Paulo.

GALLI, L.M.P. Autoconhecimento como Habilidade Profissional para as Relações Públicas: Um enfoque da Gestalt-terapia. 2000. 187f. Dissertação (Mestrado em Comunicação Social) - Pontifícia Universidade Católica do Rio Grande do Sul, Porto Alegre.

Comunicação Contemporânea: uma visão da Fenomenologia, Gestalt-terapia e da Hermenêutica. 2007. 228f. Tese (Doutorado em Comunicação Social) - Pontifícia Universidade Católica do Rio Grande do Sul, Porto Alegre.

GOMES, P.W. Gestalt-terapia - Herança em Re-Vista. 2001. 123f. Dissertação (Mestrado em Psicologia) - Universidade Católica de Pernambuco, Recife.

Gomes, W. B.; Holanda, A.F.; Gauer, G. História das Abordagens Humanistas em Psicologia no Brasil. In: Marina Massimi (Org.). História da Psicologia no Brasil do Século XX (p.105-130). São Paulo: E.P.U., 2004b.

- Primórdios da Psicologia Humanista no Brasil. In: MASSIMI, Marina(Org.). História da Psicologia no Brasil do Século XX (p.87-104). São Paulo: E.P.U, 2004a.

GORENSTIN, S.G. Uma Contribuição ao Conceito de AutoRegulação Psicológica na Gestalt-terapia - Para Além da Homeostase. 1992. 116f. Dissertação (Mestrado em Psicologia) Universidade Federal do Rio de Janeiro, Rio de Janeiro. 
GRANZOTTO, R.L. Gênese e Construção de uma "Filosofia da Gestalt" na Gestalt-terapia. 2005. 131f. Dissertação (Mestrado em Filosofia) - Universidade Federal de Santa Catarina, Florianópolis.

HOLANDA, A.F.; FARIA, N.J. (Orgs). Gestalt-terapia e Contemporaneidade. Contribuições para uma Construção Epistemológica da Teoria e Prática Gestáltica. Campinas: Editora Livro Pleno, 2005.

HOLANDA, A.F.; KARWOWSKI, S.L. Produção Acadêmica em Gestaltterapia no Brasil: Análise de Mestrados e Doutorados. Psicologia, Ciência e Profissão [online]. Vol.24, n.2, p.60-71 Disponível em: http://pepsic. bvs-si.org.br/scielo. php?script=sci_arttext\&pid=S141498932004000200008\&lng=pt\&nrm=iso. Acesso em: 17 mai 2008. HOLANDA, A.F. Carl Rogers e Martin Buber: Abordagem Centrada na Pessoa e Filosofia Dialógica em Questão. 1993 214f. Dissertação (Mestrado em Psicologia) - Universidade de Brasília, Brasília.

. Elementos de Epistemologia da Gestalt-terapia, In: Adriano F. Holanda; Nilton Julio de Faria (Orgs). Gestalt-terapia e Contemporaneidade: Contribuições para uma construção epistemológica da teoria e da prática gestáltica, Campinas: Livro Pleno, 2005. [p.21-53].

IVANCKO, S. M. Uma compreensão psicossomática do órgão de choque através do trabalho com polaridades. 2006. $283 \mathrm{f}$. Dissertação (Mestrado em Psicologia Clínica) - Pontifícia Universidade Católica de São Paulo, São Paulo.

KARWOWSKI, S.L. Gestalt-terapia e Fenomenologia. Considerações sobre o método fenomenológico em Gestalt-terapia. Campinas: Livro Pleno, 2005.

O Método Fenomenológico na Gestalt-terapia Segundo Formadores de Gestalt-terapeutas. 2002. 134f. Dissertação (Mestrado em Psicologia Clínica) - Pontifícia Universidade Católica de Campinas, Campinas.

KATO, M.L. Contribuições do Enfoque Dialógico de Buber para o Ensino da Psicologia. 1991. 68f. Dissertação (Mestrado em Psicologia) - Universidade de São Paulo, São Paulo.

KIYAN, A.M.M. Dentro e Fora da Lata do Lixo: Uma análise gestáltica das articulações entre vida e obra de Frederick Perls. 1998. 188f. Dissertação (Mestrado em Psicologia) - Universidade São Marcos, São Paulo.

. E a Gestalt Emerge. Vida e Obra de Frederick Perls. São Paulo, Altana, 2001.

LILIENTHAL, L.A. A Gestaltpedagogia sai às ruas para trabalhar com crianças e educadores de rua. 1997. 208f. Dissertação (Mestrado em Psicologia) - Universidade de São Paulo, São Paulo.

Educa-São: Uma possibilidade de atenção em ação. 2004. 217f. Tese (Doutorado em Psicologia) - Universidade de São Paulo, São Paulo. 
LIMA FILHO, A.P. Estudos sobre o Método de Experimentos com Sonhos na Concepção de Frederick Perls. 1990. $290 \mathrm{f}$. Dissertação (Mestrado em Psicologia) - Universidade de São Paulo, São Paulo.

\author{
. Gestalt e Sonhos. São Paulo: Summus, 2002.
}

LIIMA, M.M.C. Análise e Avaliação do Processo de Mudança em um Grupo Fechado de Gestalt-terapia: Estudo de Caso. 1988. 311f. Dissertação (Mestrado em Psicologia Clínica) - Universidade de Brasília, Brasília.

LIMA, P.V.A. Psicoterapia e Mudança - Uma reflexão. 2005. $261 \mathrm{f}$. Tese (Doutorado em Psicologia) - Universidade Federal do Rio de Janeiro, Rio de Janeiro.

. Repensando o Campo Teórico da Gestalt-terapia. 1997. 96ff. Dissertação (Mestrado em Psicologia) - Universidade Federal do Rio de Janeiro, Rio de Janeiro.

LIMA, S.A.S. A Criança Hiperativa como uma Totalidade em Ação: Uma visão gestáltica segundo a Teoria do Ciclo do Contato. 2002. 201f. Dissertação (Mestrado em Psicologia) - Universidade de Brasília, Brasília.

LOFFREDO, A.M. A Cara e o Rosto. Ensaio sobre Gestalt-terapia. São Paulo: Escuta, 1994.

- De Cotovelos Apoiados no Para-Peito da Palavra: Do Cenário Clínico, Qual é o Horizonte?. 1992. 264f. Tese (Doutorado em Psicologia) - Universidade de São Paulo, São Paulo.

MORAES, C.C. Trabalhando com os Fenômenos Religiosos e Espirituais: Uma proposta metodológica para avaliação da experiência de ampliação de consciência no processo grupal. 2002. 226f. Tese (Doutorado em Psicologia Clínica) - Universidade de Brasília, Brasília.

MÜLLER-GRANZOTTO, M.J.; MÜLLER-GRANZOTTO, R.L. Fenomenologia e Gestalt-terapia. São Paulo: Summus, 2007. PENTEADO, C.A.S. O Conceito de Inconsciente na Gestaltterapia. 1998. 131f. Dissertação (Mestrado em Psicologia) Universidade de São Paulo, São Paulo.

PERLS, F.S. Escarafunchando Fritz: dentro e fora da lata do lixo. São Paulo: Summus, 1979.

PHILIPPI, M.M. Co-construindo Pontes entre a Gestalt-terapia e as Terapias Sistêmicas Construtivistas Construcionistas Sociais: Subjetividade e Intersubjetividade em Questão. 2004. $237 \mathrm{f}$. Dissertação (Mestrado em Psicologia Clínica) - Universidade de Brasília, Brasília.

PIMENTEL, A. O Psicodiagnóstico em Gestalt-terapia. 2002. $236 \mathrm{f}$. Tese (Doutorado em Psicologia Clínica) - Pontifícia Universidade Católica de São Paulo, São Paulo.

Psicodiagnóstico em Gestalt-terapia. Summus, 2003. 
PINTO, E.B. Gestalt-terapia de Curta Duração para Clérigos Católicos: Elementos para a prática clínica. 2007. 268f. - Tese (Doutorado em Ciências da Religião) - Pontifícia Universidade Católica de São Paulo, São Paulo.

PORTO, R.C. Bases Filosóficas e I mplicações Técnicas na Gestalt-terapia. 1989. 115f. Dissertação (Mestrado em Psicologia) Fundação Getúlio Vargas, Rio de J aneiro.

QUADROS, L.C.T. Diagnóstico em Gestalt-terapia: Possibilidades e Limites. 1991. 92f. Dissertação (Mestrado em Psicologia) Universidade Federal do Rio de J aneiro, Rio de Janeiro.

ROCHA, S.L.C.O. Psicogênese da Masculinidade: Uma leitura gestáltica sobre a construção da identidade do gênero masculino em diversas teorias e sua importância para a escola. 2001. $308 f$. Dissertação (Mestrado em Educação) - Universidade Federal do Ceará, Fortaleza.

SILVEIRA, T.M. A Construção Criativa na Vida do Casal: Limites e Possibilidades do Casamento Contemporâneo. 1998. 82f. Dissertação (Mestrado em Psicologia) - Pontifícia Universidade Católica do Rio de J aneiro, Rio de Janeiro.

TÁVORA, C.B. Psicoterapia e Individualismo: Análise TeóricoPrática dos Limites e Possibilidades de um Projeto para a Clínica no Discurso da Gestalt-terapia. 1994. 87f. Dissertação (Mestrado em Psicologia) - Universidade do Estado do Rio de Janeiro, Rio de Janeiro.

TELLEGEN, T.A. Elementos de Psicoterapia Guestáltica. Boletim de Psicologia (Sociedade de Psicologia de São Paulo), Vol.XXIV, JulDez, N.64, p.21-26, 1972.

TELLEGEN, T.A. Gestalt e Grupos. São Paulo: Summus, 1994.

Reflexões sobre Trabalho com Grupos na Abordagem Gestáltica em Psicoterapia e Educação. 1982. 102f. Dissertação (Mestrado em Psicologia) - Universidade de São Paulo, São Paulo.

TENÓRIO, C.M.D. Os Transtornos da Personalidade Histriônica e Obsessivo-Compulsiva na Perspectiva da Abordagem Gestáltica e da Teoria de Fairbairn. 2003. 291f. Tese (Doutorado em Psicologia Clínica) - Universidade de Brasília, Brasília.

VASCONCELOS, C.M.D. Os Distúrbios da Fronteira de Contato Um Estudo Teórico e Empírico em Gestalt Terapia. 1994. 181f. Dissertação (Mestrado em Psicologia Clínica) - Universidade de Brasília, Brasília.

VERAS, R.P. I lumina-ação: diálogos entre a Gestalt-terapia e o ZenBudismo. 2005. 172f. Dissertação (Mestrado em Psicologia Clínica) Pontifícia Universidade Católica de São Paulo, São Paulo.

ZANELLA, R. Contatuando com Figura e Fundo: Uma contribuição à psicoterapia de grupo infantil na abordagem gestáltica em psicoterapia. 1992. 163f. Dissertação (Mestrado em Psicologia) Instituto Metodista de Ensino Superior, São Bernardo do Campo. 
ZLOTNIC, S. Gestalt-terapia e Transferência: Aquisição de Conceitos na Formação de Psicólogos. 1990. 112f. Dissertação (Mestrado em Psicologia) - Universidade de São Paulo, São Paulo.

ZURBA, M.C. A Abordagem Gestáltica e Construtivista na Compreensão do Desenvolvimento da Autonomia e da Subjetividade de Jovens em Situação de Risco durante o Uso do Sistema Hipernet. 1997. 130f. Dissertação (Mestrado em Psicologia do Desenvolvimento) - Universidade Federal do Rio Grande do Sul, Porto Alegre.

\author{
Endereço para correspondência \\ Adriano Furtado Holanda \\ Departamento de Psicologia, Universidade Federal do Paraná, Ala Alfredo Buffren, \\ Praça Santos Andrade, 50 / Sala 215, CEP 80060-240, Curitiba-PR, Brasil \\ Endereço eletrônico: aholanda@yahoo.com
}

Recebido em: 14/06/2008

Aceito para publicação em: 01/07/2008

Editor responsável: Laura Cristina de Toledo Quadros

\begin{abstract}
Notas
* Doutor em Psicologia / Universidade Federal do Paraná

1 Consoante informações disponibilizadas pela ABEP (Associação Brasileira do Ensino da Psicologia), no site www.abepsi.org.br, igualmente dispostos no site do INEP (http://www.educacaosuperior.inep.gov.br/).

2 Informações disponíveis na Capes (Coordenação de Aperfeiçoamento de Pessoal de Nível Superior), em www.capes.gov.br

${ }^{3}$ Estamos considerando a contagem temporal das décadas a partir do ano 1 de cada uma delas. Portanto, consideramos a década de 1990 a partir do ano 1991, e assim por diante.

${ }^{4}$ Este destaque deve-se ao fato que, após a nova regulamentação do Ensino Superior nacional (Decreto do Ministério da Educação, No 3.860, de 9 de julho de 2001), foi estabelecida uma nova classificação das Instituições de Ensino Superior (IES) como sendo: Universidades (que se caracterizam pela oferta regular de atividades de ensino, pesquisa e extensão), Centros Universitários (que enfatizam basicamente o ensino) e as Faculdades Integradas, Faculdades, Institutos ou Escolas Superiores (instituições com propostas curriculares em mais de uma área o conhecimento). No que tange especificamente à pesquisa (e que comumente, mas não necessariamente, está vinculado a programas de pós-graduação), um dos critérios básicos para o desenvolvimento destas atividades é a titulação do seu corpo docente, o que demanda das Universidades uma qualificação mais rigorosa do que os Centros Universitários (que são na sua imensa maioria, instituições privadas de ensino).
\end{abstract}

